\title{
Composition of Plasma ApoA-I-Containing Lipoprotein Particles in Children and Adults
}

\author{
E. D. BEKAERT, ${ }^{1}$ P. ALAUPOVIC, C. KNIGHT-GIBSON, P. BLACKETT, \\ AND M. AYRAULT-JARRIER \\ Oklahoma Medical Research Foundation, Oklahoma City, Oklahoma 73104 [E.D.B., P.A., C.K.-G.]; Department \\ of Pediatrics, University of Oklahoma Health Science Center, Oklahoma City, Oklahoma 73104 (P.B.): and \\ INSERM U32, Hopital Henri Môndor, 94010 Créteil, France [M.A.-J.]
}

\begin{abstract}
The purpose of this study was to examine sex- and age-related differences in the concentration and composition of lipoprotein particles containing apoA-I (LPA-I) and those containing apoA-I and apoA-II (LP-I:A-II), the main HDL as defined by their apolipoprotein composition. Lipoproteins were isolated by immunoaffinity chromatography of whole plasma from 16 normal prepubertal children and 15 normal male and female adults using "pan"-MAb to apoA-I and apoA-II. Although there was no difference between children and adults in the concentration of LP-A-I:A-II, adult females had significantly higher levels of LP-A-I than either children or adult males. Main differences between children and adults as well as between adult males and females were in the apolipoprotein composition of the lipoprotein particles; children had the highest content of minor apolipoproteins (apoC and $\mathrm{apoE}$ ) in LP-A-I but the lowest in LP-A-I:A-II. The lipid/apolipoprotein ratios of LP-A-I and LP-A-I:A-II were significantly higher in children and women than in men. The LP-A-I and LP-A-I:A-II contained $75 \%$ of the total plasma apoC and apoE in women and children but only $50 \%$ in men. However, in all three groups, $70-90 \%$ of the minor HDL apolipoproteins were associated with LP-A-I:A-II. The nonmolar ratios of minor apolipoproteins in LP-A-I and LP-A-I:A-II and the sex- and age-related differences in apoA-I/apoA-II ratios of LP-A-I:A-II suggest that both lipoproteins may consist of a spectrum of lipoprotein subfamilies differing in their apolipoprotein composition. Results of this study indicate that the age- and sex-related differences in the levels and composition of LP-A-I and LP-A-I:A-II relate primarily to changes in the protein moieties of these particles. (Pediatr Res 29: 315-321, 1991)
\end{abstract}

\section{Abbreviations}

LP-A-I, lipoprotein particle containing apoA-I

LP-A-I:A-II, lipoprotein particle containing apoA-I and apoA-II

HDL-C, HDL-cholesterol

TG, triglyceride

PL, phospholipid

CE, cholesterol ester

FC, free cholesterol

Received June 4, 1990; accepted October 31, 1990

Correspondence and reprint requests: P. Alaupovic, Ph.D., Lipoprotein and Atherosclerosis Research Program, Oklahoma Medical Research Foundation, 825 N.E. 13th Street, Oklahoma City, OK 73104.

Supported in part by funding from NIH Grant HL-23181 and the resources of the Oklahoma Medical Research Foundation. E.D. was sponsored by the Comité des Aides à la Recherche Fournier, Dijon, France.

' Present address: Inserm U32, Hôpital Henri Mondor, 94010 Créteil, France.
Previous evidence clearly supports heterogeneity of operationally defined plasma lipoprotein classes with respect to their chemical composition and metabolic properties $(1-3)$. For example, by utilizing apolipoproteins as specific markers for identifying and classifying discrete lipoprotein particles in plasma, it has been shown that apoB- and apoA (apoA-I and apoA-II)containing lipoproteins form two major groups of plasma lipoproteins $(1,2)$. The apoB-containing lipoproteins are located in the very low and low density ranges, whereas the apoA-containing lipoproteins are present in the high and very high density ranges of the lipoprotein density spectrum. The latter group consists of two major lipoprotein families referred to on the basis of their characteristic apolipoprotein composition as LP-A-I:AII and LP-A-I. The isolation and partial characterization of these two lipoprotein families have been described in reports from several laboratories (4-11).

So far, the LP-A-I:A-II and LP-A-I particles have been isolated mainly from plasma of normolipidemic adults. However, because the human lipid transport system has been shown to undergo several changes from its fetal to adult form $(2,12-15)$, the purpose of this study was to provide information on the concentration and composition of these two major HDL families in plasma of normal, prepubertal children of both sexes and to compare them with those of adults.

\section{SUBJECTS}

A group of 16 normolipidemic children (10 males and six females), aged 4 to $9 \mathrm{y}$, were randomly selected from patients admitted to the outpatient surgical facility of the Oklahoma Children's Memorial Hospital for minor surgical procedures. All children were healthy, asymptomatic, and without family history of hyperlipoproteinemia or diabetes; they had normal weight and height for their age groups. The conditions under which the blood samples were drawn were unstressful. There was minimal anticipation of the event; it took place soon after the parents, waiting with their children in a playroom, had given their written consent. Blood samples were collected into vacutainer tubes containing disodium EDTA $(1.5 \mathrm{mg} / \mathrm{mL})$ and the plasma was promptly separated by low centrifugation $(1000 \times g)$ at $4^{\circ} \mathrm{C}$.

The adult population consisted of seven male and eight female volunteers randomly selected from a pool of normolipidemic employees of the Oklahoma Medical Research Foundation according to some predetermined selection criteria (2). All subjects were healthy, asymptomatic Caucasians with no history of familial hyperlipoproteinemia or diabetes. Their weight/height index was between 0.9 and 1 . They were all nonsmokers except for one of the male subjects who consumed 10 cigarettes/d. Only two male subjects were regular alcohol drinkers, but their alcohol consumption did not exceed $50 \mathrm{~g} /$ wk. All women were premenopausal and none was using contraceptive agents. With the exception of one male subject, age $64 \mathrm{y}$, the mean age of men 
$(34.8 \pm 6.7 \mathrm{y})$ was very similar to that of women $(35.6 \pm 8.5 \mathrm{y})$. Informed consent was obtained from each adult volunteer. After an overnight fast, blood samples were drawn and plasma samples were prepared as already described for children.

\section{MATERIALS AND METHODS}

Production and characterization of $M A b$ to apoA-I and apoAII. MAb F59 4A12 2F4 (anti-apoA-I) and CdBs (anti-apoA-II) were produced, purified, and characterized as previously described $(16,17)$. These antibodies were selected on the basis of their specificity and binding capacity to the major circulating forms of corresponding apolipoproteins.

Preparation of anti-apoA-I and anti-apoA-II immunosorbers. MAb to apoA-I and apoA-II were coupled to the cross-linked agarose activated with N-hydroxysuccinimide (Affi-Gel 10) purchased from Bio-Rad Laboratories (Richmond, CA). After exhaustive washing of Affi-Gel with ice-cold, double-distilled, deionized water, the solubilized antibodies were added to the gel slurry $(0.8 \mathrm{mg}$ of $\mathrm{Ig} / \mathrm{mL}$ of gel) and the mixture was gently shaken for $2 \mathrm{~h}$ at room temperature. The gel was allowed to settle and the supernatant solution was carefully removed. To block the remaining active sites, the gel was incubated overnight with 0.5 $\mathrm{M}$ Tris- $\mathrm{HCl}$ buffer containing $1.5 \mathrm{M} \mathrm{NaCl}, \mathrm{pH} 7.4$, at $4^{\circ} \mathrm{C}$. The Econo-columns $(1.5 \times 30 \mathrm{~cm}$; Bio-Rad Laboratories) were first packed with $30 \mathrm{~mL}$ of Sephadex G-25 (Pharmacia, Piscataway, $\mathrm{NJ}$ ) followed by $20 \mathrm{~mL}$ of antibody-coupled Affi-Gel and another protective layer of $2.5 \mathrm{~mL}$ of Sephadex G-25. The purpose of Sephadex G-25 layers was to shorten the exposure time between the lipoprotein and dissociating agent (18). Each column was extensively washed free of nonadsorbed proteins with three volumes of $3 \mathrm{M}$ sodium thyocyanate and reequilibrated with $0.5 \mathrm{M}$ Tris- $\mathrm{HCl}$ buffer, $\mathrm{pH} 7.4$, containing $0.15 \mathrm{M} \mathrm{NaCl}$ and $1.5 \mathrm{~g} / \mathrm{L}$ EDTA. The binding capacities of the anti-apoA-I and anti-apoAII immunosorbers were $0.018 \mathrm{mg}$ of apoA-I and $0.027 \mathrm{mg}$ of apoA-II $/ \mathrm{mL}$ of gel, respectively. The antibody-coupled immunosorbers were stable for more than six mo at $4^{\circ} \mathrm{C}$ without loss of binding capacity.

Isolation and fractionation of apoA-I-containing lipoproteins by immunoaffinity chromatography. Fresh plasma $(2 \mathrm{~mL})$ was applied to the anti-apoA-I immunosorber and incubated overnight at $4^{\circ} \mathrm{C}$. The unretained fraction was washed off with 0.05 $\mathrm{M}$ Tris- $\mathrm{HCl}$ buffer, $\mathrm{pH} 7.4$, containing $0.15 \mathrm{M} \mathrm{NaCl}$ and $1.5 \mathrm{~g}$ / L EDTA. ApoA-I-containing lipoproteins bound to the column were then desorbed and eluted with $3 \mathrm{M}$ sodium thyocyanate at a flow rate of $30 \mathrm{~mL} / \mathrm{h}$. The retained fraction was concentrated in dialysis bags using polyvinyl-pyrrolidone PVP-40 (Sigma Chemical Co., St. Louis, MO) outside the bags, then applied to the anti-apoA-II immunosorber without overloading. Both the unretained (LP-A-I) and the retained (LP-A-I:A-II) fractions were eluted and concentrated as described above. The unretained fraction was tested for the possible presence of apoA-II by electroimmunoassay. Fractions containing immunochemically detectable apoA-II were rechromatographed on anti-apoA-II immunsorber and only unretained fractions free of apoA-II were used for measuring the distribution of apoA-I between retained (LP-A-I:A-II) and unretained (LP-A-I) fractions. The recoveries of apoA-I ranged between 78 and $92 \%$ of applied apoA-I. The concentrations of apoA-I in LP-A-I and LP-A-I:A-II particles were calculated on the basis of plasma apoA-I values and the percent distribution of apoA-I in retained and unretained fractions from anti-apoA-II immunosorber.

Apolipoprotein and lipid analyses. Quantitative determination of apoA-I, -A-II, -B, -C-II, -C-III, -D, and -E in plasma and in LP-A-I and LP-A-I:A-II was carried out by previously described electroimmunoassays (19-24). Total cholesterol and TG in the plasma were determined by enzymatic procedures as previously described (25). HDL-C was estimated according to the procedure of Lipid Research Clinics Program (26). These three assays were standardized with serum calibrators and control samples supplied by the Centers for Disease Control, Atlanta, GA. TG, CE, and FC of lipoprotein particles and CE and FC in whole plasma were quantified by a gas-liquid chromatographic procedure of Kuksis et al. (27). PL phosphorus content was determined by the method of Gerlach and Deuticke (28).

Statistical evaluation. All values, where appropriate, were expressed as mean \pm SD. Statistical differences were assessed by the $t$ test. The level of significance was regarded as $p<0.05$.

\section{RESULTS}

Plasma lipid and apolipoprotein levels. The plasma lipid and apolipoprotein concentrations of the normolipidemic children and adults are shown in Tables 1 and 2 . There were no significant differences in the lipid profiles between the male and female children. However, the concentration of total cholesterol was significantly lower in children of both sexes than in adults. The plasma TG levels were significantly lower in male children but not in female children in comparison with corresponding adults. As a group, children also had significantly lower plasma PL levels than adults. Although men and women had significantly higher levels of HDL-C than male and female children, these differences were not statistically significant. The values of the CE/FC ratio of whole plasma were within the normal range in children and adults of both sexes. There were no differences in the concentrations of apoA-I, -A-II, -B, and -D between male and female children. However, despite almost identical levels of TG, female children had significantly higher levels of apoC-II, apoC-III, and apoE than male children. In contrast, the concentrations of apoCII and -C-III, but not apoE, were significantly lower in adult females than males; women also had significantly higher concentrations of apoA-I and lower concentrations of apoA-II and apoB than men. As a group, children had significantly lower concentrations of all apolipoproteins, with the exception of apoE, than the adult population.

Plasma levels of apolipoprotein A-I associated with $L P-A-I$ and $L P-A-I: A-I I$. The levels of apoA-I were determined in the fractions containing LP-A-I and LP-A-I:A-II after concentrating with PVP-40. Because there was no difference between male and female children in the concentrations of apoA-I associated with either LP-A-I or LP-A-I:A-II, these results were combined and children were treated as a single group (Table 3). The apoA-I concentrations associated with LP-A-I in adult females were significantly higher than those in adult males and children $(p<$ 0.01 ). In contrast, there was no significant difference between adult males and children in the levels of apoA-I associated with LP-A-I. When LP-A-I concentrations were expressed in terms of total lipid and protein mass, the LP-A-I levels in adult females $(148.6 \pm 31.2 \mathrm{mg} / \mathrm{dL})$ were still significantly higher $(p<0.05$ versus children and $p<0.01$ versus adult males) than in children $(121.0 \pm 20 \mathrm{mg} / \mathrm{dL})$ or adult males $(92.8 \pm 30.4 \mathrm{mg} / \mathrm{dL})$ However, because the lipid but not the protein mass of LP-A-I was higher in children than in adult males, the levels of LP-A-I particles expressed in terms of lipid and protein mass were higher in children $(p<0.05)$ than in men. All three groups of normolipidemic subjects had similar concentrations of apoA-I associated with LP-A-I:A-II and similar levels of LP-A-I:A-II expressed in terms of their lipid and protein mass $(348 \pm 75,340 \pm 46$, and $384 \pm 54 \mathrm{mg} / \mathrm{dL}$ for children, males, and females, respectively). It appears, therefore, that significantly higher values of plasma apoA-I in women $(p<0.05)$ are mainly accounted for by the higher concentrations of apoA-I associated with LP-A-I particles.

Percent lipid compositions of LP-A-I and LP-A-I:A-II. As shown in Table 4 , there were no significant differences in the percent lipid composition of LP-A-I and LP-A-I:A-II isolated from children as a single group and adult males and females as separate groups. However, the percentage of TG in LP-A-I was significantly higher in men than in women $(p<0.05)$. When the percent lipid composition of LP-A-I was compared with that of 
Table 1. Plasma lipid levels ( $\mathrm{mmol} / \mathrm{L}$ ) in normolipidemic children and adults*

\begin{tabular}{cccccc}
\hline Subjects & TC & TG & PL & HDL-C & CE/FC \\
\hline Children & & & & & \\
Male $(n=10)$ & $3.70 \pm 0.65^{c}$ & $0.50 \pm 0.21^{e}$ & $2.80 \pm 0.41$ & $1.28 \pm 0.32$ & $4.0 \pm 0.33$ \\
Female $(n=6)$ & $3.63 \pm 0.73^{d}$ & $0.53 \pm 0.28$ & $2.81 \pm 0.39$ & $1.32 \pm 0.37$ & $3.6 \pm 0.77$ \\
Total $(n=16)$ & $3.67 \pm 0.66^{\prime}$ & $0.51 \pm 0.23$ & $2.81 \pm 0.40^{h}$ & $1.30 \pm 0.37$ & $3.9 \pm 0.56$ \\
Adults & & & & & \\
Male $(n=7)$ & $5.30 \pm 1.11^{c}$ & $1.14 \pm 0.58^{a, c^{\prime}}$ & $3.80 \pm 0.55$ & $1.34 \pm 0.24$ & $3.9 \pm 0.45$ \\
Female $(n=8)$ & $5.35 \pm 0.89^{d}$ & $0.56 \pm 0.16^{a}$ & $3.70 \pm 0.30$ & $1.57 \pm 0.24$ & $4.1 \pm 0.47$ \\
Total $(n=15)$ & $5.33 \pm 0.93^{\prime}$ & $0.78 \pm 0.46$ & $3.75 \pm 0.40^{\prime \prime}$ & $1.48 \pm 0.26$ & $4.0 \pm 0.46$ \\
\hline
\end{tabular}

* Mean $\pm \mathrm{SD}$; all values are expressed as $\mathrm{mmol} / \mathrm{L}$ except for $\mathrm{CE} / \mathrm{FC}$, which is a weight ratio. TC, total cholesterol. Means marked with the same letter are significantly different at: ${ }^{a . h} p<0.05 ;{ }^{c \cdot d c^{\prime}} p<0.01 ;^{\prime} p<0.001$.

Table 2. Plasma apolipoprotein levels in normolipidemic children and adults*

\begin{tabular}{|c|c|c|c|c|c|c|c|}
\hline \multirow[b]{2}{*}{ Subjects } & \multicolumn{7}{|c|}{ Apolipoproteins (mg/dL) } \\
\hline & A-I & A-II & B & $\mathrm{C}-\mathrm{II}$ & C-III & $\mathrm{D}$ & $E$ \\
\hline \multicolumn{8}{|l|}{ Children } \\
\hline Male $(n=10)$ & $\begin{array}{l}126.2 \\
(14.8)\end{array}$ & $\begin{array}{l}70.9 \\
(8.9)\end{array}$ & $\begin{array}{c}67.5 \\
(15.0)\end{array}$ & $\begin{array}{r}1.6^{c} \\
(0.4)\end{array}$ & $\begin{array}{r}4.6^{a} \\
(1.5)\end{array}$ & $\begin{array}{c}7.9 \\
(1.9)\end{array}$ & $\begin{array}{r}9.3^{d} \\
(2.6)\end{array}$ \\
\hline Female $(n=6)$ & $\begin{array}{l}128.9 \\
(21.9)\end{array}$ & $\begin{array}{c}72.8 \\
(10.6)\end{array}$ & $\begin{array}{c}68.0 \\
(13.2)\end{array}$ & $\begin{array}{r}2.6^{\circ} \\
(0.7)\end{array}$ & $\begin{array}{c}6.1^{a} \\
(1.5)\end{array}$ & $\begin{array}{c}8.6 \\
(2.0)\end{array}$ & $\begin{array}{l}12.9^{d} \\
(3.3)\end{array}$ \\
\hline Total $(n=16)$ & $\begin{array}{l}127.2^{f} \\
(17.0)\end{array}$ & $\begin{array}{l}71.6^{6} \\
(9.2)\end{array}$ & $\begin{array}{r}67.7^{\prime} \\
(13.9)\end{array}$ & $\begin{array}{r}2.0^{\prime \prime} \\
(0.7)\end{array}$ & $\begin{array}{c}5.1^{m} \\
(1.4)\end{array}$ & $\begin{array}{r}8.2^{\prime \prime} \\
(1.9)\end{array}$ & $\begin{array}{l}10.7 \\
(3.3)\end{array}$ \\
\hline \multicolumn{8}{|l|}{ Adults } \\
\hline Male $(n=7)$ & $\begin{array}{l}133.5^{\circ} \\
(14.5)\end{array}$ & $\begin{array}{r}90.4^{R} \\
(10.6)\end{array}$ & $\begin{array}{l}109.4^{i} \\
(20.0)\end{array}$ & $\begin{array}{r}3.4^{k} \\
(1.2)\end{array}$ & $\begin{array}{l}10.7^{\prime} \\
(2.4)\end{array}$ & $\begin{array}{l}15.9 \\
(4.6)\end{array}$ & $\begin{array}{l}11.8 \\
(3.6)\end{array}$ \\
\hline Female $(n=8)$ & $\begin{array}{l}151.7^{\circ} \\
(13.8)\end{array}$ & $\begin{array}{c}76.5^{8} \\
(4.8)\end{array}$ & $\begin{array}{r}77.4^{i} \\
(13.4)\end{array}$ & $\begin{array}{c}2.1^{k} \\
(0.7)\end{array}$ & $\begin{array}{r}7.8^{i} \\
(1.3)\end{array}$ & $\begin{array}{l}14.4 \\
(2.5)\end{array}$ & $\begin{array}{l}11.2 \\
(2.6)\end{array}$ \\
\hline Total $(n=15)$ & $\begin{array}{l}143.2^{f} \\
(16.5)\end{array}$ & $\begin{array}{r}82.2^{h} \\
(10.3)\end{array}$ & $\begin{array}{r}92.3^{j} \\
(23.1)\end{array}$ & $\begin{array}{r}2.7^{h} \\
(1.1)\end{array}$ & $\begin{array}{c}9.1^{\prime \prime} \\
(2.4)\end{array}$ & $\begin{array}{l}15.2^{n} \\
(3.7)\end{array}$ & $\begin{array}{l}11.5 \\
(3.0)\end{array}$ \\
\hline
\end{tabular}

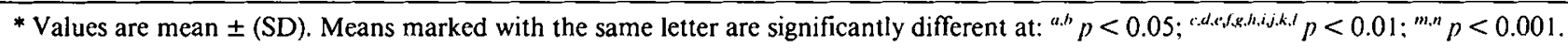

Table 3. Plasma levels of apoA-I associated with LP-A-I and LP-A-I:A-II particles*

\begin{tabular}{|c|c|c|c|c|}
\hline \multirow[b]{2}{*}{ Subjects } & \multicolumn{2}{|c|}{ LP-A-I } & \multicolumn{2}{|c|}{ LP-A-I:A-II } \\
\hline & $\mathrm{mg} / \mathrm{dL}$ & $\%$ of total apoA-I & $\mathrm{mg} / \mathrm{dL}$ & $\%$ of total apoA-I \\
\hline Children $(n=16)$ & $38.2 \pm 7.8$ & $30.2 \pm 5.5$ & $89.0 \pm 15.8$ & $69.8 \pm 5.5$ \\
\hline Adult males $(n=7)$ & $38.5 \pm 11.1$ & $28.9 \pm 6.2$ & $93.0 \pm 9.3$ & $71.1 \pm 6.2$ \\
\hline Adult females $(n=8)$ & $54.4 \pm 11.0 \dagger$ & $35.6 \pm 4.6$ & $97.3 \pm 7.4$ & $64.4 \pm 4.6$ \\
\hline
\end{tabular}

$*$ Values are mean \pm SD.

$\uparrow$ Mean significantly different $(p<0.01)$ from those of adult males and children.

Table 4. Percent lipid composition of LP-A-I and LP-A-I:A-II particles*

\begin{tabular}{|c|c|c|c|c|}
\hline Subjects & TG & $\mathrm{CE}$ & $\mathrm{FC}$ & PL \\
\hline \multicolumn{5}{|l|}{ LP-A-I } \\
\hline Children $(n=16)$ & $3.8 \pm 2.9$ & $25.5 \pm 4.4$ & $6.7 \pm 1.4$ & $64.0 \pm 5.6$ \\
\hline Male adults $(n=7)$ & $4.5 \pm 1.8^{a}$ & $26.5 \pm 4.5$ & $5.9 \pm 1.2$ & $63.1 \pm 3.8$ \\
\hline Female adults $(n=8)$ & $2.1 \pm 1.1^{a}$ & $24.9 \pm 4.1$ & $7.7 \pm 1.9$ & $65.3 \pm 4.8$ \\
\hline \multicolumn{5}{|l|}{ LP-A-I:A-II } \\
\hline Children $(n=16)$ & $4.0 \pm 2.2$ & $30.2 \pm 2.4$ & $5.5 \pm 1.1$ & $60.3 \pm 3.4$ \\
\hline Male adults $(n=7)$ & $3.9 \pm 1.1$ & $32.4 \pm 2.8$ & $5.5 \pm 0.5$ & $58.1 \pm 3.9$ \\
\hline Female adults $(n=8)$ & $3.4 \pm 1.2$ & $31.6 \pm 6.2$ & $6.6 \pm 1.3$ & $58.4 \pm 6.5$ \\
\hline
\end{tabular}

* Values are mean \pm SD. Means marked with the same letter are significantly different at: ${ }^{a} p<0.05$.

LP-A-I:A-II, the mean values for CE/FC ratios were always higher in LP-A-I:A-II (adults: $5.3 \pm 12$; children: $5.6 \pm 1.0$ ) than in LP-A-I from the same populations (adults: $3.9 \pm 1.3$; children: $3.8 \pm 0.8$ ). The higher CE/FC ratio in LP-A-I:A-II reflected a higher content of $\mathrm{CE}$ at the expense of PL content and, to a lesser extent, at the expense of FC content when compared with LP-A-I.

Percent apolipoprotein compositions of LP-A-I and LP-A-I:AII. The percent apolipoprotein composition of LP-A-I and LPA-I:A-II was affected by both the sex and age of normolipidemic subjects (Table 5 and 6 ). There are, however, some common characteristics regarding the apolipoprotein composition of these lipoprotein families. First, apoA-I in LP-A-I and apoA-I and apoA-II in LP-A-I:A-II account for approximately $85 \%$ of the total protein content of these particles. Second, in both lipoprotein families regardless of sex and age, apoC-II and apoC-III account for approximately $5 \%$ and apoD and apoE for approximately $10 \%$ of their total protein content.

The LP-A-I particles from female adults had a significantly lower percentage content of apoC-III and -E $(p<0.01$ and $p<$ 0.05 , respectively) and a higher percentage content of apoA-I ( $p$ $<0.05)$ than those from young subjects. However, there were no significant differences in the apolipoprotein composition of LP. A-I between children and adult males. The LP-A-I:A-II particles 
BEKAERT $E T A L$.

Table 5. Percent apolipoprotein composition of LP-A-I particles*

\begin{tabular}{|c|c|c|c|c|c|}
\hline \multirow[b]{2}{*}{ Subjects } & \multicolumn{5}{|c|}{ Apolipoproteins } \\
\hline & A-I & C-II & C-III & $\mathrm{D}$ & E \\
\hline $\begin{array}{l}\text { Children }(n=16) \\
\text { Male adults }(n=7) \\
\text { Female adults }(n=8)\end{array}$ & $\begin{array}{l}85.1 \pm 5.6^{a} \\
88.0 \pm 7.8 \\
91.0 \pm 6.9^{a}\end{array}$ & $\begin{array}{l}1.3 \pm 1.4 \\
0.4 \pm 0.4 \\
0.7 \pm 0.7\end{array}$ & $\begin{array}{l}4.8 \pm 2.4^{b} \\
2.8 \pm 3.7 \\
1.9 \pm 1.5^{b}\end{array}$ & $\begin{array}{l}5.0 \pm 2.9 \\
5.6 \pm 2.8 \\
5.2 \pm 4.8\end{array}$ & $\begin{array}{l}3.8 \pm 2.9^{c} \\
3.2 \pm 2.8 \\
1.1 \pm 1.7^{c}\end{array}$ \\
\hline
\end{tabular}

* Values are mean \pm SD. Means marked with the same letter are significantly different at: ${ }^{a, c} p<0.05 ;{ }^{b} p<0.01$.

Table 6. Percent apolipoprotein composition of LP-A-I:A-II particles*

\begin{tabular}{llccccc}
\hline & \multicolumn{5}{c}{ Apolipoproteins } \\
\cline { 2 - 7 } \multicolumn{1}{c}{ Subjects } & \multicolumn{1}{c}{ A-I } & A-II & C-II & C-III & D & E \\
\hline Children $(n=16)$ & $52.6 \pm 3.0^{a}$ & $34.6 \pm 2.3^{c}$ & $1.1 \pm 1.2$ & $1.4 \pm 0.7^{e}$ & $4.0 \pm 1.2^{f}$ & $4.5 \pm 2.2^{g}$ \\
Male adults $(n=7)$ & $49.3 \pm 2.2^{a, b}$ & $38.3 \pm 2.3^{d}$ & $0.8 \pm 0.4$ & $2.1 \pm 24$ & $7.1 \pm 1.4^{f}$ & $2.4 \pm 0.7^{g, h}$ \\
Female adults $(n=8)$ & $52.8 \pm 4.7^{b}$ & $32.9 \pm 4.8^{c, d}$ & $1.0 \pm 0.5$ & $2.6 \pm 2.2^{e}$ & $1.1 \pm 1.7^{c}$ & $5.5 \pm 3.1^{h}$ \\
\hline
\end{tabular}

*Values are mean $\pm \mathrm{SD}$. Means marked with the same letter are significantly different at: ${ }^{a, b, c, d, g, h} p<0.05 ;{ }^{c} p<0.01 ;{ }^{\prime} p<0.0001$.

from adult males had significantly lower relative contents of apoA-I and apoE $(p<0.05)$ and a higher percentage of apoD ( $p$ $<0.001$ ) than those from children or adult females.

The molar ratio of apoA-I to apoA-II in LP-A-I:A-II particles from adult females $(1.02 \pm 0.18)$ was higher than that in LP-AI:A-II particles from prepubertal children $(0.9 \pm 0.08)$ or adult males $(0.8 \pm 0.7)$.

Distribution of minor apolipoproteins among apoA-I-containing lipoprotein particles. In children and adult females, more than $75 \%$ of the total plasma apoC-II, apoC-III, and apoE contents were associated with apoA-I-containing lipoprotein particles. In contrast, only $50 \%$ of these apolipoproteins were associated with apoA-I-containing lipoprotein particles in plasma of normolipidemic adult males. Approximately $88 \%$ of the total plasma apoD was bound to apoA-I-containing lipoproteins.

Results in Table 7 show that, of the total content of minor apolipoproteins associated with apoA-I, approximately $75 \%$ were bound to LP-A-I:A-II and 25\% to LP-A-I. However, there were some sex-and age-related differences in the distribution of these apolipoproteins. For example, in plasma of prepubertal children, about $50 \%$ of the total apoC-III associated with apoA-I was detected in LP-A-I. In plasma of adult females, more than $90 \%$ of the total apoE associated with apoA-I was bound to LP-AI:A-II, whereas in plasma of adult males $90 \%$ of the total apoCII was bound to LP-A-I:A-II. Men also had a higher proportion of apoD in LP-A-I:A-II (85\%) than women or children.

Lipid/apolipoprotein ratios of LP-A-I and LP-A-I:A-II. The apolipoprotein contents of LP-A-I and LP-A-I:A-II are expressed as the sum of all separately measured apolipoproteins. In general, the lipid/apolipoprotein ratios of LP-A-I were higher than those of LP-A-I:A-II in all subjects (Table 8). However, the LP-A-I from men contained less lipids than those from women or children. Similarly, the relative lipid content of LP-A-I:A-II from adult males was lower than that of either adult females or children. However, there were no significant differences in lipid/ apolipoprotein ratios of LP-A-I and LP-A-I:A-II between children and women.

\section{DISCUSSION}

The well-documented negative correlation between the concentration of HDL or HDL-C and coronary artery disease (2933) has been one of the main reasons for continuing interest in the chemical and metabolic properties of this group of lipoproteins. Studies on the chemical and immunologic characterization have shown that HDL represent a heterogeneous population of particles differing not only in hydrated density and size but also in lipid and apolipoprotein composition $(1,34,35)$. This marked heterogeneity of HDL is mainly due to the well-documented occurrence of distinct, polydisperse families of lipoprotein particles of similar physical properties but different and specific apolipoprotein composition (1,34-37). Albers and Aladjem (4) were the first to identify and separate by immunoprecipitation two major, discrete HDL particles, one of which contained apoAI and apoA-II (LP-A-I:A-II) and the other only apoA-I (LP-A-I) as the integral protein constituents (4). This finding has been confirmed by several authors utilizing immunoaffinity chromatography with polyclonal antisera to apoA-I and apoA-II as the procedure of choice for isolating LP-A-I and LP-A-I:A-II (5-10). The present study shows that immunosorbers with pan-MAb to apoA-I and apoA-II may also be used for the fractionation and quantitative isolation of these two lipoprotein families in agreement with similar results recently reported by James et al. (11). It should be pointed out that MAb to apoA-I used in both of these studies are directed to the C-terminal region of apoA-I shown to be well expressed on the surface of lipoprotein particles $(38,39)$.

It has been shown in this comparative study that sexually mature males and females had higher concentrations of all lipids and apolipoproteins than prepubertal children. There were no differences in the lipid levels and only slight differences in the

Table 7. Plasma concentrations of minor apolipoproteins associated with LP-A-I and LP-A-I:A-II particles*

\begin{tabular}{|c|c|c|c|c|c|c|c|c|}
\hline \multirow[b]{3}{*}{ Subjects } & \multicolumn{8}{|c|}{ Apolipoproteins $(\mathrm{mg} / \mathrm{dL})$} \\
\hline & \multicolumn{2}{|c|}{$\mathrm{C}-\mathrm{HI}$} & \multicolumn{2}{|c|}{ C-III } & \multicolumn{2}{|c|}{$\mathrm{D}$} & \multicolumn{2}{|r|}{ E } \\
\hline & LP-A-I & LP-A-I:A-II & LP-A-I & LP-A-I:A-II & LP-A-I & LP-A-I:A-II & LP-A-I & LP-A-I:A-II \\
\hline Children $(n=16)$ & $\begin{array}{r}0.43^{a} \\
(0.22)\end{array}$ & $\begin{array}{c}1.32 \\
(0.60)\end{array}$ & $\begin{array}{c}2.11^{b} \\
(1.19)\end{array}$ & $\begin{array}{c}2.25^{c} \\
(1.17)\end{array}$ & $\begin{array}{c}1.82 \\
(0.71)\end{array}$ & $\begin{array}{l}5.85^{\text {d.e }} \\
(1.39)\end{array}$ & $\begin{array}{c}1.68 \\
(1.41)\end{array}$ & $\begin{array}{c}6.74 \\
(2.28)\end{array}$ \\
\hline Adult males $(n=7)$ & $\begin{array}{r}0.21^{a} \\
(0.25)\end{array}$ & $\begin{array}{c}1.51 \\
(0.87)\end{array}$ & $\begin{array}{c}1.68 \\
(2.39)\end{array}$ & $\begin{array}{c}3.06 \\
(2.39)\end{array}$ & $\begin{array}{c}1.92 \\
(1.00)\end{array}$ & $\begin{array}{l}10.87^{d} \\
(1.55)\end{array}$ & $\begin{array}{c}1.78 \\
(2.38)\end{array}$ & $\begin{array}{r}4.53^{f} \\
(1.23)\end{array}$ \\
\hline Adult females $(n=8)$ & $\begin{array}{c}0.48 \\
(0.40)\end{array}$ & $\begin{array}{c}1.79 \\
(0.74)\end{array}$ & $\begin{array}{r}1.12^{b} \\
(0.80)\end{array}$ & $\begin{array}{r}4.66^{c} \\
(2.05)\end{array}$ & $\begin{array}{c}2.53 \\
(2.22)\end{array}$ & $\begin{array}{r}8.42^{e} \\
(2.81)\end{array}$ & $\begin{array}{c}0.78 \\
(1.25)\end{array}$ & $\begin{array}{r}8.15^{f} \\
(3.18)\end{array}$ \\
\hline
\end{tabular}

* Values are mean $\pm(\mathrm{SD})$. Means marked with the same letter are significantly different: ${ }^{a . h s} p<0.05 ;{ }^{c, c} p<0.01 ;^{d} p<0.001$. 
Table 8. Percent lipid and apolipoprotein composition of LP-A-I and LP-A-I:A-II particles*

\begin{tabular}{cccc}
\hline \multicolumn{1}{c}{ Subjects } & Lipids & Apolipoproteins & $\begin{array}{c}\text { Lipid/apolipoprotein } \\
\text { ratio }\end{array}$ \\
\hline LP-A-I & & & 1.69 \\
$\quad$ Children $(n=16)$ & $62.9 \pm 5.1$ & $37.1 \pm 5.1$ & 1.00 \\
Adult males $(n=7)$ & $50.1 \pm 2.5 \dagger$ & $49.9 \pm 2.5$ & 1.56 \\
Adult females $(n=8)$ & $61.0 \pm 2.3$ & $39.0 \pm 2.3$ & 1.03 \\
LP-A-I:A-II & & & 0.79 \\
Children $(n=16)$ & $50.8 \pm 2.9$ & $49.2 \pm 2.9$ & 1.05 \\
Adult males $(n=7)$ & $44.2 \pm 2.9 \dagger$ & $55.8 \pm 2.9$ & $48.7 \pm 3.9$ \\
Adult females $(n=8)$ & $51.3 \pm 3.9$ & & \\
\hline
\end{tabular}

* Values are mean $\pm \mathrm{SD}$.

+ Mean significantly different $(p<0.001)$ from those of adult females and children.

concentrations of apoC-II, -C-III, and -E between prepubertal boys and girls. However, the concentration and chemical composition of LP-A-I and LP-A-I:A-II isolated from the prepubertal children differed from those isolated from men and women. These results also provided evidence that the already documented sex-related difference in the concentration and composition of these two lipoprotein families in the adult population $(10,40)$ occurs after sexual maturation.

The percentage distribution of apoA-I between LP-A-I and LP-A-I:A-II in children was similar to that in adults, indicating that $25-40 \%$ of the total apoA-I remains in LP-A-I. Although within a similar range, these results tend to be slightly lower than the reported values for the percentage of apoA-I (30-45\%) associated with LP-A-I (8-11, 40-42). However, in contrast to a similar distribution of apoA-I between LP-A-I and LP-A-I:A-II in all age groups of normolipidemic subjects, the concentrations of these lipoprotein families, expressed in terms of apoA-I contents, were found to be slightly lower in prepubertal children than in adults. The most characteristic change from prepubertal to adult state was a significant increase in the levels of LP-A-I in women with little or no change in men. Because there was no significant sex-related difference in concentrations of adult LPA-I:A-II, it appears that the well-documented increase in the levels of apoA-I in women $(2,40,43-45)$ is due mainly to the elevation of LP-A-I. The elevation of LP-A-I levels in women was also accompanied by a compositional change in this lipoprotein family in that the relative content of apoA-I increased and that of minor apolipoproteins decreased in comparison with its childhood form. These results confirm and extend those of Koren et al. (40) and März et al. (46), who have also concluded that the higher concentrations of plasma apoA-I observed in women than in men may be accounted for by the higher concentration of LP. A-I. Ohta et al. (42) have also reported that women have higher levels of LP-A-I than men but, in contrast to findings of this study, they have ascribed this difference to a decrease of LP-A-I in men rather than an increase of these particles in women. The reason(s) for this discrepancy is not obvious but may possibly be due to the selection of adult populations in these two studies. In the former study, both men and women were younger than in the present study and had similar, if not identical, levels of plasma apoA-I. In view of the slightly decreasing effect of testosterone (47) and increasing effect of estrogens (48) on the concentrations of plasma apoA-I, it is possible that even slight differences or changes in the ratios of these gonadal hormones may be an important factor in regulating the levels of LP-A-I.

It has recently been shown (41) that the concentration of LPA-I, but not LP-A-I:A-II, is lower in male patients with angiographically documented coronary artery disease than in patients without the disease or in normal controls. This observation may be accounted for by the capacity of LP-A-I, but not LP-A-I:A-II, to acquire cholesterol from cultured peripheral cells $(49,50)$, suggesting that the potentially antiatherogenic effect of LP-A-I might be mediated through their participation in reverse cholesterol transport.

Although the concentration of apoA-I in LP-A-I:A-II was slightly higher in adult women than in children or adult males, these differences were not statistically significant. Age or sex had no effect on the percent lipid composition of LP-A-I:A-II, but some significant changes occurred in the apolipoprotein composition of this lipoprotein family. Among these, the most significant was that LP-A-I:A-II from men had lower apoA-I and apoE and higher apoD contents than those from children and women. In contrast to some experimental data supporting the putative antiatherogenic potential of LP-A-I, no such evidence is available for a similar antiatherogenic effect of LP-A-I:A-II. However, LP-A-I:A-II might exert such effect in their role as a possible link in the well-documented inverse relationship between HDL and TG-rich lipoproteins (51). It has been proposed that one of the main functions of LP-A-I:A-II (52) may be to serve as the major acceptor and reservoir of apoC-peptides and apoE released during the lipolytic degradation of TG-rich lipoproteins $(35,52,53)$. Results of this study have now demonstrated that, regardless of sex and age, LP-A-I:A-II contain 70$90 \%$ of the total HDL content of apoC-II, -C-III, -D, and -E and, thus, may function as the main acceptors of these apolipoproteins (Table 7). A similar distribution of apoD and apoE was also reported by Cheung and Albers (54). Minor sex-related differences include a higher proportion of apoC-III in adult LP-A-I:AII and a predominance of apoD in male and apoE in female LPA-I:A-II.

This study has also revealed some interesting sex- and agerelated differences in the chemical structure of LP-A-I and LPA-I:A-II. A comparison of lipid composition between homologous LP-A-I and LP-A-I:A-II has shown that the CE/FC ratios of the former are always higher than those of the latter in agreement with similar findings by other investigators $(10,42$, $54,55)$. However, the lipid/apolipoprotein ratios of LP-A-I and LP-A-I:A-II in men were found to be significantly lower than in children or women, providing at least a partial explanation for the relatively low concentration of $\mathrm{HDL}_{2}$ subfraction in men in comparison with women (34). Another significant sex-related structural difference pertains to the molar ratios of apoA-I/apoAII in LP-A-I:A-II decreasing in the order of women (1.02) > children $(0.90)>$ men $(0.80)$. These values differ from those (1.5-2.0) reported in the literature (8-10). Because most results on apoA-I measurements in plasma are within a relatively narrow range of values, the observed difference in the apoA-I/apoA-II ratio is most probably due to the use of different secondary standards for determining the absolute concentration of apoAII. However, whatever the true value of apoA-II may be, the difference in the observed molar ratios of apoA-I/apoA-II seems to reflect a sex- and age-related heterogeneity of LP-A-I:A-II. Before discussing the possible causes of this heterogeneity, it should be pointed out that apoA-I accounts for approximately $85 \%$ of the total protein of LP-A-I, whereas apoA-I and apoA-II account for approximately the same percentage of the total protein of LP-A-I:A-II. Because they occur in nonmolar ratios, minor apolipoproteins cannot be present on all LP-A-I and LPA-I:A-II. Preliminary results from this laboratory (unpublished experiments), based on sequential immunoprecipitation of these 
two lipoprotein families with antisera to apoC-III, -D, -E, have shown that approximately $70-75 \%$ of LP-A-I and LP-A-I:A-II are devoid of all minor apolipoproteins and that apoD and apoE are apparently not bound to the same LP-A-I or LP-A-I:A-II. These results, consistent with the existence of complex subspecies such as LP-A-I:D:lecithin cholesterol acyltransferase:cholesterol ester transfer protein described recently by Francone et al. (56), demonstrate the microheterogeneity of LP-A-I and LP-A-I:A-II brought about and defined by varying contents and proportions of minor apolipoproteins. We speculated that this compositional heterogeneity of LP-A-I:A-II may be the underlying cause for the sex-related difference in the apoA-I/apoA-II molar ratio of this lipoprotein family. For example, the apoA-I/apoA-II molar ratio of a LP-A-I:A-II:D subfamily occurring mainly in men and that of a LP-A-I:A-II:E subfamily present in a higher concentration in women cannot be the same. The reason for this is the presence in LP-A-I:A-II:E of small amounts of the apoE:apoA-II complex (57); the presence of apoA-II in this complex as a monomer leads to an increased molar ratio of apoA-I/apoA-II.

Results of this study show that the age- and sex-related differences in the concentration and composition of apoA-containing lipoprotein families reflect changes in the protein moieties of these lipoproteins. Furthermore, LP-A-I:A-II may function as the main acceptor of apoC peptides and apoE released during the lipolytic degradation of TG-rich lipoproteins and both LPA-I and LP-A-I:A-II may consist of several subfamilies differentiated on the basis of their apolipoprotein composition. Finally, these results support the already documented chemical and metabolic uniqueness of LP-A-I and LP-A-I:A-II $(9,34,49,50)$ and indicate the need for further studies on their composition and function.

Acknowledgments. The authors thank Clinton Corder, M.D., for supplying plasma samples from adult subjects; members of the Department of Anesthesiology, the University of Oklahoma Health Sciences Center, for samples from normal children; Cindy Brown and Randy Whitmer for their excellent technical assistance; and Margo French for typing and editing this manuscript.

\section{REFERENCES}

1. Osborne Jr JC, Brewer Jr HB 1977 The plasma lipoproteins. Adv Protein Chem 31:253-337

2. Alaupovic P, McConathy WJ, Fesmire J, Tavella M, Bard JM 1988 Profiles of apolipoproteins and apolipoprotein B-containing lipoprotein particles in dyslipoproteinemias. Clin Chem 34:B13-B27

3. Lippel K, Gianturco S, Fogelman A, Nestel P, Grundy SM, Fisher W, Chait A, Albers J, Roheim PS 1987 Lipoprotein heterogeneity workshop. Arteriosclerosis 7:315-323

4. Albers JJ, Aladjem F 1971 Precipitation of ${ }^{125}$ I-labeled lipoproteins with specific pol; peptide antisera. Evidence for two populations with differing polypeptide compositions in human high density lipoproteins. Biochemistry 10:3436 3442

5. Suenram A, Alaupovic P 1977 Isolation of lipoprotein A (LP-A) and lipoprotein A-I (LP-A-I) by immunosorption: evidence for the lipoprotein heterogeneity of normal human HDL. In: Schettler G, Goto I, Hata I, Klose G (eds) Atherosclerosis IV. Springer Verlag, New York, pp 248-249

6. Norfeldt PIP, Olofsson SO, Fager G, Bondjers G 1981 Isolation and partial characterization of the lipoprotein families $A$ and A-I from high-density lipoproteins of human serum. Eur J Biochem 118:1-8

7. Nestruck AC, Niedmann PD, Wieland H, Seidel D 1987 Chromatofocusing of human high density lipoproteins and isolation of lipoproteins $A$ and A-I. Biochim Biophys Acta 753:65-73

8. Cheung MC, Albers JJ 1982 Distribution of high density lipoprotein particles with different apoprotein composition: particles with A-I and A-II and particles with A-I but no A-II. J Lipid Res 23:747-743

9. Atmeh RF, Shepherd J, Packard CJ 1983 Subpopulations of apolipoprotein A-I in human high-density lipoproteins. Their metabolic profiles and response to drug therapy. Biochim Biophys Acta 751:175-188

10. Ohta T, Hattori S, Nishiyama S, Matsuda I 1988 Studies on the lipid and apolipoprotein compositions of two species of apoA-I-containing lipoproteins in normolipidemic males and females. J Lipid Res 29:721-728

11. James RW, Hochstrasser D, Tissot JD, Funk M, Appel R, Barja F, Pellegrin C, Muller AF, Pometta D 1988 Protein heterogeneity of lipoprotein particles containing apolipoprotein A-I without apolipoprotein A-II and apolipoprotein A-I with apolipoprotein A-II isolated from human plasma. J Lipid Res 29:1557-1571
12. Persson B, Gentz J 1966 The pattern of blood lipids, glycerol and ketone bodies during the neonatal period, infancy and childhood. Acta Paediatr Scand 55:343-362

13. McConathy WJ, Lane DM 1980 Studies on the apolipoproteins and lipoproteins of cord serum. Pediatr Res 14:757-761

14. Tamir I, Heiss G, Glueck CJ, Christensen B, Kwiterovich P, Rifkind BM 198 Lipid and lipoprotein distributions in white children ages 6-19 yr. The Lipid Research Clinics Program Prevalence Study. J Chronic Dis 34:27-39

15. Lane DM, McConathy WJ 1986 Changes in the serum lipids and apolipoproteins in the first four weeks of life. Pediatr Res 20:332-337

16. Bekaert ED, Ayrault-Jarrier M, Petit E, Betourné C, Robin H, Polonovski J 1988 Competitive enzyme inhibition immunoassay of apolipoprotein A-I: use of monocional antibodies. Clin Chem 34:1030-1035

17. Dashti N, Koren E, Alaupovic P 1989 Identification and partial characterization of discrete apolipoprotein A-containing lipoprotein particles secreted by human cell line HepG2. Biochem Biophys Res Commun 163:574-580

18. McConathy WJ, Koren E, Wieland H, Campos EM, Lee DM, Kloer HU, Alaupovic P 1985 Evaluation of immunoaffinity chromatography for isolating human lipoproteins containing apolipoprotein B. J Chromatogr 342:4766

19. Curry MD, Alaupovic $P$, Suenram CA 1976 Determination of apolipoprotein $A$ and its constitutive $\mathrm{AI}$ and AII polypeptides by separate electroimmunoassays. Clin Chem 22:315-322

20. Curry MD, Gustafson A, Alaupovic P, McConathy WJ 1978 Electroimmunoassay, radioimmunoassay, and radial immunodiffusion assay evaluated for quantification of human apolipoprotein B. Clin Chem 24:280-286

21. Curry MD, McConathy WJ, Fesmire JD, Alaupovic P 1981 Apolipoprotein $\mathrm{C}-\mathrm{I}$ and $\mathrm{C}$-II levels in human plasma by separate electroimmunoassays. Clin Chem 27:543-548

22. Curry MD, McConathy WJ, Fesmire JD, Alaupovic P 1980 Quantitative determination of human apolipoprotein CIII by electroimmunoassay. Biochim Biophys Acta 617:503-513

23. Curry MD, McConathy WJ, Alaupovic P 1977 Quantitative determination of human apolipoprotein $\mathrm{D}$ by electroimmunoassay and radial immunodiffusion. Biochim Biophys Acta 491:232-241

24. Curry MD, McConathy WJ, Alaupovic P, Ledford JD, Popovic M 1976 Determination of human apolipoprotein $\mathrm{E}$ by electroimmunoassay. Biochim Biophys Acta 439:413-425

25. Wang CS, Alaupovic P, Gregg RE, Brewer Jr HB 1987 Studies on the mechanism of hypertriglyceridemia in Tangier disease. Determination of plasma lipolytic activites, $\mathrm{k}_{1}$ values and apolipoprotein composition of the major lipoprotein density classes. Biochim Biophys Acta 920:9-19

26. Lipid Research Clinics Program: manual of laboratory operations, Vol 1. Lipid and Lipoprotein Analysis 1974 DHEW publication no (NIH) 75-628. National Institutes of Health, Bethesda, MD

27. Kuksis A, Myher JJ, Marai L, Geher L 1975 Determination of plasma lipid profiles by automated gas chromatography and computerized data analysis. J Chromatogr Sci 13:423-430

28. Gerlach E, Deuticke B 1963 Eine einfache Methode zur Microbestimmung von Phosphat in der Papierchromatographie. Bichem Z 337:477-479

29. Barr DP, Russ EM, Eder HA 1951 Protein-lipid relationships in human plasma. II. In atherosclerosis and related conditions. Am J Med 11:480-493

30. Nikkilä E 1953 Studies on the lipid-protein relationships in normal and pathologic sera and the effect of heparin on serum lipoproteins. Scand J Clin Lab Invest [Suppl] 5:158-171

31. Gofman JW, Young W, Tandy R 1966 Ischemic heart disease, atherosclerosis and longevity. Circulation 34.679-697

32. Miller GJ, Miller NE 1975 Plasma-high-density lipoprotein concentration and development of ischaemic heart disease. Lancet 1:16-19

33. Jacobs DR, Mebane IL, Bangdiwala SI, Criqui MH, Tyroler HA 1990 High density lipoprotein cholesterol as a predictor of cardiovascular disease mortality in men and women-the follow-up study of the Lipid Research Clinics Prevalence Study. Am J Epidemiol 131:32-47

34. Alaupovic P 1984 The physiochemical and immunological heterogeneity of human plasma high-density lipoproteins. In: Miller NE, Muller GJ (eds) Clinical and Metabolic Aspects of High-Density Lipoproteins. Elsevier Science Publishers BV, Amsterdam, pp 1-44

35. Eisenberg S 1984 High density lipoprotein metabolism. J Lipid Res 25:10171058

36. Borut TC, Aladjem F 1971 Immunochemical heterogeneity of human high density serum lipoproteins. Immunochemistry 8:851-863

37. Kostner G, Alaupovic P 1972 Studies of the composition and structure of plasma lipoproteins. Separation and quantification of the lipoprotein families occurring in the high density lipoproteins of human plasma. Biochemistry 11:3419-3428

38. Schonfeld G, Bradshaw RA, Chen JS 1979 Structure of high density lipoprotein. The immunologic reactivities of the $\mathrm{COOH}$ - and $\mathrm{NH} 2$-terminal regions of apolipoprotein A-I. J Biol Chem 251:3921-3926

39. Mao SJT, Miller JP, Gotto Jr AM, Sparrow JT 1980 The antigenic structure of apolipoprotein A-I in human high density lipoproteins. Radioimmunoassay using surface specific antibodies. J Biol Chem 255:3448-3453

40. Koren E, Puchois P, Alaupovic P, Fesmire J, Kandoussi A, Fruchart JC 1978 Quantification of two different types of apolipoprotein A-I containing lipoprotein particles in plasma by enzyme-linked differential-antibody immunosorbent assay. Clin Chem 33:38-43

41. Puchois P, Kandoussi A, Fievet P, Fourrier JL, Bertrand M, Koren E, Fruchart 
JC 1987 Apolipoprotein A-I containing lipoproteins in coronary artery disease. Atherosclerosis 68:35-40

42. Ohta $\Upsilon$ Hattori S, Murakami M, Nishiyama S, Matsuda I 1989 Age- and sexrelated differences in lipoproteins containing apoprotein A-I. Arteriosclerosis 9:90-95

43. Albers JJ, Wahl PW, Cabana VG, Hazzard WR, Hoover JJ 1976 Quantification of apolipoprotein A-I of human plasma high density lipoprotein. Metabolism 25:633-644

44. Avogaro P, Cazzolato G, Bittolo Bon G, Quincy GB, Chinello M 1979 Values for apo $A_{1}$ and apoB in humans according to age and sex. Clin Chim Acta 95:311-315

45. Phillip NR, Havel RJ, Kane JP 1982 Serum apolipoprotein A-1 levels. Relationship to lipoprotein lipid levels and selected demographic variables. Am J Epidemiol 116:302-313

46. März W, Trommlitz M, Gross W 1988 Differential turbidimetric assay for subpopulations of lipoproteins containing apolipoprotein A-I. J Clin Chem Clin Biochem 26:573-578

47. Thompson PD, Cullinane EM, Sady SP, Chenever C, Saritelli AL, Sady MA, Herbert PN 1989 Contrasting effects of testosterone and stanozolol on serum lipoprotein levels. JAMA 261:1165-1168

48. Schaefer EJ, Foster DM, Zech LA, Lindgren FT, Brewer HB, Levy RI 1983 The effects of estrogen administration on plasma lipoprotein metabolism in premenopausal females. J Clin Endocrinol Metab 57:262-267

49. Fielding CJ, Fielding PE 1981 Evidence for a lipoprotein carrier in human plasma catalyzing sterol efflux from cultured fibroblasts and its relationship to lecithin:cholesterol acetyltransferase. Proc Natl Acad Sci USA 78:39113914
50. Barbaras R, Puchois P, Fruchart JC, Ailhaud G 1987 Cholesterol efflux from cultured adipose cells is mediated by $\mathrm{LpA}_{I}$ particles but not by $\operatorname{LpA}_{I}: \mathrm{A}_{\mathrm{I}}$ particles. Biochem Biophys Res Commun 142:63-69

51. Nikkilä EA, Taskinen MR, Sane T 1987 Plasma high-density lipoprotein concentration and subfraction distribution in relation to triglyceride metabolism. Am Heart J 113:543-548

52. Alaupovic P 1981 David Rubenstein Memorial lecture: the biochemical and clinical significance of the interrelationship between very low density and high density lipoproteins. Can J Biochem 59:565-579

53. Larosa JC, Levy RI, Brown WV, Fredrickson DS 1971 Changes in high-density lipoprotein protein composition after heparin-induced lipolysis. Am J Physiol 220:785-791

54. Cheung MC, Albers JJ 1984 Characterization of lipoprotein particles isolated by immunoaffinity chromatography. Particles containing A-I and A-II and particles containing A-I but no A-II. J Biol Chem 259:12201-12209

55. James RW, Proudfoot A, Pometta D 1989 Immunoaffinity fractionation of high-density lipoprotein sublcasses 2 and 3 using anti- apolipoprotein A-I and anti-apolipoprotein A-II immunosorbent gels. Biochem Biophys Acta 1002:292-301

56. Francone OM, Gurakar A, Fielding CJ 1989 Distribution and functions of lecithin:cholesterol acyltransferase and cholesteryl ester tranfer protein in plasma lipoproteins. Evidence for a functional unit containing these activities together with apolipoproteins A-I and D that catalyzes the esterification and transfer of cell-derived cholesterol. I Biol Chem 264:7066-7072

57. Weisgraber KH, Mahley RW 1978 Apolipoprotein (E-A-II) complex of human plasma lipoproteins. I. Characterization of this mixed disulfide complex and its identification in a HDL subfraction. J Biol Chem 253:628! -6289 